canicula may just as likely be Procyon, and the redness may have been due to its low altitude at the time of its first appearance in the sky after sunset. Hyginus and Germanicus Cæsar use the word candidus, that is, bright or shining white, in referring to the colour of the star. It is at least strange that Mars should have been so constantly, and Sirius so sparingly, referred to as red, and that not Sirius, but Alpha Scorpii should have been referred to as Anti-Mars (Antares). On the whole, Dr. Samter thinks the evidence is in favour of a very nearly white colour, as at present. The real explanation of the matter probably lies in the fact, pointed out some time ago in these columns, that the ancients observed Sirius at the heliacal rising, when it necessarily appeared red.

\section{THE NEW GOVERNMENT LABORATORIES.}

THE new Government Laboratory is built on a rectangular plot of land, 120 feet long by 65 feet wide, in Clement's Inn Passage, adjacent to King's College Hospital.

The exterior of the building is faced with red bricks with bands, corners and windows of Portland stone, and consists of four floors surrounded by an area whose retaining wall is faced with white glazed bricks. Central corridors run from end to enc of the building on the basement and ground floors; a staircase at each end and a hydraulic lift give access to the various floors. The main entrance faces the gateway leading into Clement's Inn, and at the opposite end are two entrances for service purposes.

The architectural treatment of the first and second floors differs wholly from that of the ground-floor and basement: the entire central portion of the building forms one large room, 49 feet long by 43 feet wide, lighted by eight lofty mullioned windows and a flat-roofed dormer lantern, the open roof being carried on light iron principals. The floor of this room is about five feet above the ceiling level of the ground-floor rooms, and the space thus gained is utilised in raising the height of the principal rooms on the groundfloor, and as a duct, seven feet wide, below the floor of the central room, for holding the heating appliances, and water, gas and drainage pipes. The remainder of the building is divided into two sections by this room: each section consists of two floors with flat asphalted roofs, one roof carrying the water cisterns, and the other affording space for operations which it is desirable should be performed in the open air, a spiral iron staircase affording the necessary access.

The ground-floor corridor has a mosaic pavement, and with the exception of a few rooms in the basement, which, as well as the other corridors, are "granolithic." all the rooms have pitchpine parqueterie flooring. The interior walls of all the laboratories, store rooms, and corridors, are faced with white glazed brick relieved by an ornamental dado of coloured glazed bricks the only rooms with plastered walls being those intended for office purposes.

The basement floor contains a boiler house, engineer's workshop, store rooms, a mechanical laboratory, and laboratories for bacteriological work, water analysis, standardising scientific instruments, and verifying the hydrometers and saccharometers used in the Revenue Service. The mains for gas, water, and steam are carried along the corridor immediately below the ceiling, and are supported on light iron girders, every pipe being in view throughout its entire length. Underneath the corridor floor is the main ventilation shaft, a long chamber seven feet square, with which the severa ventilating shafts and fume flues are connected. A powerful fan, worked by a silent one-horse engine, keeps up the air circulation and discharges the foul air into an upcast shaft surrounding the boiler furnace flue. A "return clean water main" also runs under this corridor floor, and after picking up branch mains from all the working laboratories, ends in a concrete tank of 7000 gallons capacity. Stores for house and steam coal, and a room for refrigerating machinery, have been constructed outside the main building, the former under the street pavement and the latter also partly in the area, which is here roofed in with Hayward's lights.

The main entrance leads into the.ground floor, which contains on the left a waiting-room, the principal's private office, the reference library, and the research laboratory (a room $34 \times$ i 7 feet); on the right are the Crown contracts laboratories, a suite of three rooms having a total length of 69 feet by 17 feet, the private office of the deputy principal, and the reference sample laboratory, which is 28 feet long by 20 feet wide.

The chief feature of the first floor is the main laboratory, the central room already mentioned, adjoining which is a dark room for polarimetric work and a refrigerated room for storing samples. A short corridor leading to the main staircase gives access to two rooms for the superintending analysts and to the two tobacco laboratories.

The second floors contain photographic rooms, typewriter's office, museum, and four laboratories.

The building is lighted throughout by electricity obtained from the Strand Corporation, whose continuous Ioo-volt current is also employed for working various motors.

Rooms intended for offices have open fireplaces fitted with Teale's slow combustion stoves; the remaining rooms are heated by passing steam through iron radiators. In the main laboratory the radiators are below the floor in the central duct, and are connected with the external atmosphere by air channels covered with slate slabs, and the warm air enters the room through iron gratings which cover the duct. To prevent down draught a copper steam pipe runs all round the base of the dormer lantern; in all the other laboratories the radiators are on the slate slabs covering the air channels, usually in the centre of the room.

For ventilation, four large air shafts run from the upper corners of the main laboratory down to the basement, where they connect with the main shaft already mentioned, and in every room through which they pass there is an opening controlled by a "hit and miss" grating. The mouthpieces at the back of all the evaporation and draught closets are contained by downward flues into the same main shaft.

The water supply is from the New River Company's highpressure main, branches from which run throughout the building direct to the various tables for working filter-pumps, turbines, and similar contrivances. For other purposes the water is stored in three cisterns on the roof, having a total capacity of 7000 gallons, from which it is distributed for boiler feed and ordinary laboratory work. To economise water, all the working tables are provided with special drainage outlets, which are connected by a system of iron pipes to the "return clean water main." The water discharged through this main into the concrete tank is pumped up into the service cisterns on the roof; the only water run to the drains is that used for cleansing purposes.

For ice making and refrigerating, one of Messrs. J. and E. Hall's carbonic anhydride refrigerating machines is employed, in which "brine" is cooled by the evaporation of liquid carbonic anhydride in copper coils surrounded by the brine, the cooled brine being used for making ice, cooling water, and for maintaining a low temperature in the sample store adjoining the main laboratory. This store is an insulated chamber with hollow walls, made of steel plates placed immediately in front of the insulation, through which the cooled brine circulates. The main laboratory has been specially designed for the evaluation of spirituous liquors, in connection with which a great desideratum is a supply of water fairly uniform in temperature all the year round. In the summer months the temperature of the ordinary water is lowered by passing it from the cisterns on the roof down to the refrigerating machine-room, where it runs through a cooler fitted with coils through which cold brine circulates. From the conler the water is pumped by a centrifugal pump up to a special insulated cistern holding Iooo gallons, from which all the tables in the main laboratory are served.

The working tables have mahogany tops $\mathrm{I}_{\frac{1}{2}}$ inches thick, with fronts and ends of varnished Rigi wainscot. In all rooms, except the main laboratory, the tables are placed against the outer walls immediately underneath the windows; they stand on a 3 -inch plinth, which is protected by a recessed toe space and by making the table-top overhang 3 inches. They are uniformly 37 inches from floor to top of table, with a row of cupboards above the plinth topped by a single row of drawers. A space between the removable backs of the cupboards and the walls serves for carrying the waterpipes and draining troughs.

A white ware sink ( $12 \times 9 \times 4 \frac{1}{2}$ inches) is provided for each pair of workers, and behind it is a water standard fitted with Kelvin tap delivering into the sink, and side pipes with lever cocks 
for condensed water. The outlet of the sink connects through a wooden pipe with a V-shaped wooden trough lined with lead and pitched, which, after picking up from all the sinks in the table, discharges into a galvanised iron funnel, also coated with pitch; a continuing pipe conveys the dirty water into drains outside the building.

Fischer's brass filter pumps with vacuum gauge attached are fixed to the tables, and the water passing through them is conveyed by a system of pipes into the clean water return-main, as is also the water drawn from the side tubes of the water standard.

Sets of shelves for reagent bottles, consisting of three plates of glass supported on gun-metal brackets, are fixed on the walls at the back or ends of the tables.

In the main laboratory there are eight tables arranged in two rows, four tables being on each side of a wide central gangway, with a clear space of five feet between each table.

The tops are twelve feet long by five wide, and each table affords working space for four operators; a white ware sink ( $20 \times 9 \times 4 \frac{1}{2}$ inches) is placed at each end of the table, and the standards delivering water into the sinks serve as pillars carrying a shelf nine feet long by one foot wide, which runs down the centre of the table between the two sinks at a height of one foot above the table top. Along the under surface the wires for the electric light are carried, and a plug is fixed on each side for motor attachments.

The two water standards are connected by a water pipe running underneath the shelf, and from this pipe four branches are taken on each side for supplying water to the still condensers. This water comes from the cooled water cistern, and after doing its work is passed through nozzles fixed on the table top into a pipe running underneath along the iniddle of the table, which finally connects with the return clean water main.

The tables stand on a plinth with recessed toe space, the top overhangs three inches all round; the cupboards and drawers are similar to those already described. Between the backs of the opposite cupboards is a space similar to that between the backs of the cupboards and the walls in the other laboratories, and this space is utilised for holding the water pipes and draining trough. The gas supply pipes are carried along the fronts of the tables in all the laboratories immediately below the overhanging portion, with off-takes leading to nozzles fixed on the top of the tables at the back. These off-takes are copper tubes which pass through the framing of the drawers, the contro. cocks being in front of the table.

All the principal laboratories are provided with evaporation closets, steam sand trays, steam drying ovens, distilled water apparatus, and cabinets for holding and using standard volumetric solutions.

The evaporation closets are very similar in character to those already in use at the Yorkshire College and elsewhere. They consist of a slate slab placed in front of a flue mouthpiece; a copper conical vessel is bolted to the under surface of the slab, which is perforated with a large bevelled hole in which is fitted a white stoneware collar. This collar, together with the copper portion, forms a hollow inverted cone, passing through the slate with a base 12 inches in diameter, on which is placed a thin steel plate coated on both sides with a rubber composition called "woodite," and perforated with holes of various sizes for holding basins, capsules and similar vessels. The upper portion is enclosed in a glass case resting on the slate slab, the front being a glass door sliding up and down by means of a counterbalancing weight working over pulleys. The roof is a plate of glass sloping down from front to back, with its back edge placed just above the top of the mouthpiece. A valve placed underneath the slab admits steam into the copper under portion of the cone, and any accumulation of condensed water flows away by a pipe fixed at a level slightly lower than the steam inlet. This pipe connects with a cubical cistern of brass with plate-glass front, arranged to act as a constant level apparatus in the event of steam not being available, in which case the bath is heated by a safety Bunsen burner placed immediately below the inverted copper apex.

The drying ovens, steam sand trays, and distilled water apparatus are all constructed as constituent parts of one appliance, through which steam from a single inlet circulates. The sand tray is a shallow copper vessel $30 \times 12$ inches; below it is a copper jacket lined with tin, through which the steam passes. It is well insulated and lagged round the sides and bottom, and forms the top of an enclosed oak cabinet fitted No. I 458 , voL. 56$]$ with wooden rails for holding dusters and towels, which are dried by the waste heat. Reduced steam first passes through a steam trap which automatically discharges the accumulation of condensed water, the outlet from the sand tray being so arranged that there is always available a supply of hot distilled water which can be drawn off as required through a Kelvin bib cock placed immediately over the cabinet doors.

From the sand tray the steam passes into the drying oven, which is fixed on the wall immediately above the sand tray. This oven is a stout copper-jacketed vessel insulated and lagged, the doors being fitled with plate-glass panels. Air for ventilation is admitted at the bottom and passes through a copper coil in the steam jacket, so that on entering the bath it is heated up to the temperature of the steam, and escapes through a similar opening at the top.

From the top of the oven a copper pipe leads the excess steam into the distilled water apparatus. This is an iron cylinder supported on brackets, and contains a block-tin worm, the upper end of which is connected with the pipe from the oven. The lower end delivers distilled water into a large earthenware jar standing on a wooden pedestal. A glass cock passes through a tubulure at the bottom of the jar in front, and through a similar tubulure on the right-hand side of the jar is fitted a glass water gauge, which also serves as an automatic overflow by being bent over into a funnel placed behind the jar; this funnel also receives water from the cylinder containing the block-tin worm, and by suitable connections delivers the water into the tank under the basement.

The appliance for holding the standard solutions is a shallow cabinet of Riga wainscot fixed against the walls, with polished plate-glass top and four doors; the panels of the upper doors are of glass, and the plinth is protected by a countersunk band of brass. The bottles containing the standard solutions stand on a shelf immediately behind the glass doors, and are fitted with two-holed rubber stoppers, through which pass a soda-lime guard tube, and a glass tube dipping down to the bottom of the bottle. This glass tube is connected, by india-rubber tubing which passes through a bevelled hole in the plate-glass top, with the stoppered side tube of a burette. Each burette is held in position by a pair of small clips fixed on two parallel brass bars, the bars being supported between a pair of brackets fixed to the ends of the cabinet on the plate-glass top. These clips ensure a perfectly rigid perpendicular position, and at the same time allow the burette to be easily raised or lowered. The burettes are filled with the standard solutions by suction through the top end of the burette, which is fitted with guard-tube continued by a depending piece of india rubber to a glass mouthpiece.

The tobacco laboratory is provided also with special drying ovens and furnaces for incinerating vegetable substances. The drying ovens, three in number, are placed on the wall one above the other, and steam for heating them is generated in a special boiler standing close by, the condensed water flows back into the boiler, which is also connected with an independent water supply, having a valve and ball-cock for keeping constant level.

The carbonising and muffle furnaces are arranged in two chambers of white glazed bricks, supported on arches which spring from a large York flagstone; apertures in the roof communicating with a flue for carrying off the fumes and heated air. For carbonising the tobacco a special furnace has been designed. From the gas main in front of the chamber five branch pipes conncet with long rectangular tubes. On each tube are screwed eight brass boxes, with a lever gas-cock between each box and the tube. Near each corner of the box a small Bunsen burner is fixed, and by this means a small flame plays uniformly over the under surface of the platinum dishes, which are supported on a light wrought-iron nickel-plated grid. The furnace is capable of holding forty dishes at one time. The front of the chamber, in which the furnace stands, is closed by a counterpoised glass door sliding up and down.

The incineration of the samples is completed in three muffle furnaces, of special design, heated by gas.

The whole of the work in connection with the building and fittings has been carried out under the immediate supervision of H.M. Office of Works, from designs supplied by Dr. Thorpe, and the manner in which the work has been executed reflects the $\mathrm{h}$ ighest credit on that department.

J. WOODWARD. 